

\title{
PAISAGEM CULTURAL: TRABALHO E COTIDIANO DA IMIGRAÇÃO JAPONESA NO VALE DO RIBEIRA/SÃO PAULO
}

\section{Flávia Brito do Nascimento}

Historiadora e arquiteta, Docente do Departamento de História da Arquitetura e Estetica do Projeto na Faculdade de Arquitetura e Urbanismo da USP

\author{
Simone Scifoni \\ Geógrafa e Docente nos programas de graduação e pós-graduação em Geografia na USP \\ e membro do Conselho da Rede Paulista de Educação Patrimonial (REPEP)
}

\begin{abstract}
RESUMO
O presente artigo apresenta o estudo de bens culturais da imigração japonesa nos municípios de Registro e Iguape, São Paulo. A partir das premissas da paisagem cultural, foram estudadas várias marcas da imigração no Vale do Ribeira, que vão desde a arquitetura das habitações, os chazais, o trabalho com junco, passando pela própria cidade de Registro e pela Festa do Tooro Nagashi. Estes são importantes testemunhos da ocupação de parcela do território brasileiro através da implantação de três colônias japonesas no país: Katsura, Iguape e Sete Barras.
\end{abstract}


ID_PESQUISAS

\section{RESUMEN}

El presente artículo presenta el estudio de los bienes culturales de la emigración japonesa en los municipios de Registro e lguape, São Paulo. A partir de las premisas del paisaje cultural, se investigaron varias huellas de la emigración en la región llamada Vale do Ribeira, que van desde la arquitectura residencial, hasta las plantaciones de té, las labores del junco, pasando por la propia ciudad de Registro y por la Fiesta del Tooro Nagashi. Estos son importantes testimonios de la ocupación de parte del territorio brasileño a través del establecimiento de tres colonias japonesas en el país: Katsura, lguape y Sete Barras.

Palabras clave: paisaje cultural, emigración japonesa, labor y cotidiano

\section{ABSTRACT}

This article presents a study on cultural assets of the Japanese immigration in the towns of Registro and Iguape, in the state of São Paulo. Based on cultural landscape premises, several aspects of this immigration in the Ribeira Valley were studied - ranging from the architecture of the dwellings, the tea plantations, the work with straw, the town of Registro itself, as well as the Tooro Nagashi Festival. These are important pieces of evidence of the occupation of part of the Brazilian territory through the implementation of three Japanese colonies in the country: Katsura, Iguape and Sete Barras.

Keywords: cultural landscape, Japanese immigration, work and daily life 


\section{INTRODUÇÃO}

Diversas são as marcas da colonização japonesa no Vale do Ribeira as quais configuram hoje uma paisagem cultural singular: a arquitetura típica das habitações e edificações fabris, os campos de cultivo do chá e do junco, os caminhos vicinais e lotes do antigo núcleo colonial, os barcos iluminados no rio Ribeira de Iguape durante a celebração do Tooro Nagashi. Atribuir valor a estes testemunhos, reconhecendo-os como parte da formação do patrimônio cultural nacional foi o objetivo do estudo elaborado no âmbito do Instituto do Patrimônio Histórico e Artístico Nacional, Iphan de São Paulo, entre 2008 e 2009 e por nós coordenado. O ponto de partida do estudo foi superar a visão tradicional do patrimônio como monumento para pensá-lo a partir do trabalho e do cotidiano do sujeito imigrante em sua relação com as terras brasileiras. $O$ estudo procurou compreender como o desafio de superar os limites de uma natureza tropical, desconhecida e aparentemente hostil se concretizou na paisagem produzida por esse sujeito imigrante, assim como se realizou em suas práticas culturais fortemente vinculadas à natureza.

As contribuições dos imigrantes japoneses no Brasil são relativamente pouco conhecidas, sobretudo se comparadas às dos alemães, italianos e eslavos. O estudo realizado pelo Iphan de São Paulo buscou contribuir para o conhecimento destas expressões de nossa cultura, evidenciando o significativo potencial patrimonial existente no Vale do Ribeira, com foco específico nos bens culturais ligados à paisagem cultural e aos processos históricos da imigração. Objetivou contribuir com as ações públicas voltadas à proteção, conservação e valorização deste patrimônio, capazes de, entre outras coisas, fomentar a melhoria das condições sócio-econômicas da região. Partindo de importantes trabalhos já realizados sobre os imigrantes japoneses na região do Vale do Ribeira como os de Gonçalves, 2008, Aoki, 2006, Yamaki, 1997 e Kuniyoshi, Segawa e Pires (1985) a pesquisa pretendeu avançar no conhecimento das formas de moradia, apropriação e reapropriação do construir e do habitat do imigrante japonês e suas relações à arquitetura praticada no Japão, visando seu entendimento como paisagem cultural.

O Vale do Ribeira de Iguape, localizado na região sul do Estado de São Paulo e leste do Paraná, abrange uma área total de aproximadamente $25.000 \mathrm{~km} 2$, dos quais cerca de dois terços (17.000 km2) estão em território paulista (SMA, 1995). Embora esteja situada a pouco mais de duzentos quilômetros do maior aglomerado urbano-industrial do hemisfério, a região 
é uma das maiores e mais importantes províncias preservacionistas do país, que concentra uma extensa e complexa paisagem cultural que a singulariza regional e nacionalmente. Com uma economia baseada principalmente na pesca, agricultura (banana, chá, hortifruticultura), mineração e extrativismo vegetal (palmito) os municípios do vale são ocupados predominantemente por pequenos produtores familiares; pescadores, agricultores, gente das matas, representantes de uma sociedade artesanal e de subsistência, que se constituiu à margem das transformações que caracterizaram a sociedade brasileira do último século.

Estima-se que existam ao menos oito aldeamentos indígenas e cerca de cinquenta comunidades remanescentes de quilombos em todo o Vale, além de centenas de comunidades rurais tradicionais. Casas de pau-a-pique, roças de toco, festas de padroeiro e mutirões, remédios e doenças caseiras, compõem boa parte desta paisagem de compadres e comadres, da vida simples e em harmonia com a natureza. No entanto, é também uma região do estado de São Paulo com indicadores de pobreza elevados e cenário no qual as políticas públicas estão muito ausentes: faltam escolas, hospitais, saneamento básico, meios de comunicação e todo tipo de serviços e equipamentos públicos necessários para atender a demanda desta população por si carente.

Razões históricas, dificuldades de acesso e condições naturais adversas às atividades econômicas, determinaram, até hoje a inserção marginal do Vale nos fluxos mais intensos da dinâmica econômica do país o que permitiu que extensas áreas pudessem se manter preservadas, representando atualmente patrimônio histórico, cultural e ambiental de valor inestimável.

O estudo "Paisagem Cultural: Inventário de Conhecimento de Bens Culturais no Vale do Ribeira", foi desenvolvido pela equipe do Iphan em São Paulo no âmbito das ações de inventário do patrimônio cultural promovidas nacionalmente pelo Depam - Departamento do Patrimônio Material e Fiscalização. A perspectiva do trabalho no Vale do Ribeira foi atuar a partir dos conceitos mais abrangentes de patrimônio cultural postos em lei na Constituição de 1988, onde estão englobadas novas formas de entender as expressões intangíveis da cultura e também a natureza. Diante de tais pressupostos, buscou-se trabalhar com os conceitos de paisagem cultural para preservar e gerir o patrimônio. O olhar para o Vale do Ribeira em São Paulo possibilitou o desenvolvimento de diversos estudos na região a partir do projeto mestre de inventário de bens culturais no Ribeira. A conceituação de 
paisagem cultural levou ao estudo amplificado e inter-relacionado das expressões materiais e imateriais de cultura e dos processos urbanos e rurais de ocupação territorial. O inventário foi, portanto, estruturado multidisciplinarmente e regionalmente e teve como um de seus subprodutos o estudo dos Bens Culturais da Imigração Japonesa, que ora se apresenta.

A demanda ao Iphan para o estudo dos bens culturais da imigração japonesa no Vale do Ribeira nasceu de um encontro: o estudo realizado pela equipe técnica do Iphan em São Paulo sobre a Paisagem Cultural do Vale do Ribeira e as comemorações dos cem anos da chegada do navio Kasatu Maru no porto de Santos, ou seja, do Centenário da Imigração Japonesa no Brasil. A partir da coincidência temporal dos dois eventos, consolidou-se a iniciativa do trabalho, que se apresenta e problematiza a seguir.

\section{SUJEITO IMIGRANTE: AS COLÔNIAS JAPONESAS NO VALE DO RIBEIRA NO CONTEXTO DAS POLÍTICAS DE ESTADO}

Considerada como um grande vazio populacional, no início do século $\mathrm{XX}$, uma verdadeira fronteira a ocupar, o Vale do Ribeira, situado na região sul do estado de São Paulo, foi destino de diversas experiências de colonização estrangeira implementadas, seja por parte do poder público ou da iniciativa privada, sem, no entanto, resultar em grande sucesso. Aquela que se destacou por ter constituído uma experiência exitosa, que fixou colonos a terra e se consolidou no tempo e no espaço, criando uma paisagem peculiar, foi a imigração japonesa no município de Registro.

A colonização japonesa no Vale do Ribeira teve um caráter completamente diferenciado em relação às demais iniciativas de fixação desses imigrantes no território paulista, uma vez que esses já se instalaram na região como pequenos proprietários. Sua presença na região prende-se aos primórdios da imigração japonesa no Brasil, quando os primeiros imigrantes desembarcaram no Porto de Santos, em 1908.

O primeiro passo para viabilizar a constituição dessas colônias na região foi dado em 1912, entre o Governo do Estado de São Paulo e o Sindicato de Tóquio (Hasegawa \& Rueda, 1932). O compromisso era de doação de uma vasta extensão de terras devolutas no Vale do Ribeira, além de concessão de recursos financeiros e de isenção de impostos. Em contrapartida, a 
instituição japonesa deveria introduzir duas mil famílias na região, num período de quatro anos. O contrato foi repassado pelo Sindicato para a Brasil Takushoku Kaisha, em 30 de junho de 1913, empresa posteriormente incorporada a Kaigai Kogyo Kabushiki Kaisha (KKKK, também chamada de Kaiko ou de Companhia de Desenvolvimento Internacional). A partir de 1917, a Kaiko conduziria toda a colonização japonesa no Vale do Ribeira.

A escolha do Vale do Ribeira foi estratégica: ao percorrer o Brasil procurando terras para os colonos, o advogado do Sindicato se interessou pela ampla região de várzea, ideal para o cultivo do arroz ao qual o colono estava acostumado e, além disso, próxima ao litoral. As terras doadas pelo Estado localizavam-se junto ao porto fluvial de Registro, atual município de mesmo nome, mas que à época pertencia a Iguape. Apesar disso, foi em outro local, a quilômetros de distância e à jusante deste porto fluvial, que foi instalada a primeira colônia de japoneses no Vale: a Colônia Katsura. Os dois núcleos que se seguiram foram Registro e Sete Barras, o último a ser criado. No entanto, dos três núcleos, o único que testemunha, ainda hoje, a história da colonização japonesa expressa em sua paisagem é o de Registro.

Os três núcleos de colonização diferenciam-se quanto à origem das terras e a sua dimensão total, além de suas trajetórias de ocupação ao longo da história. Katsura e Registro fazem parte de políticas públicas promovidas para o assentamento de colonos em áreas

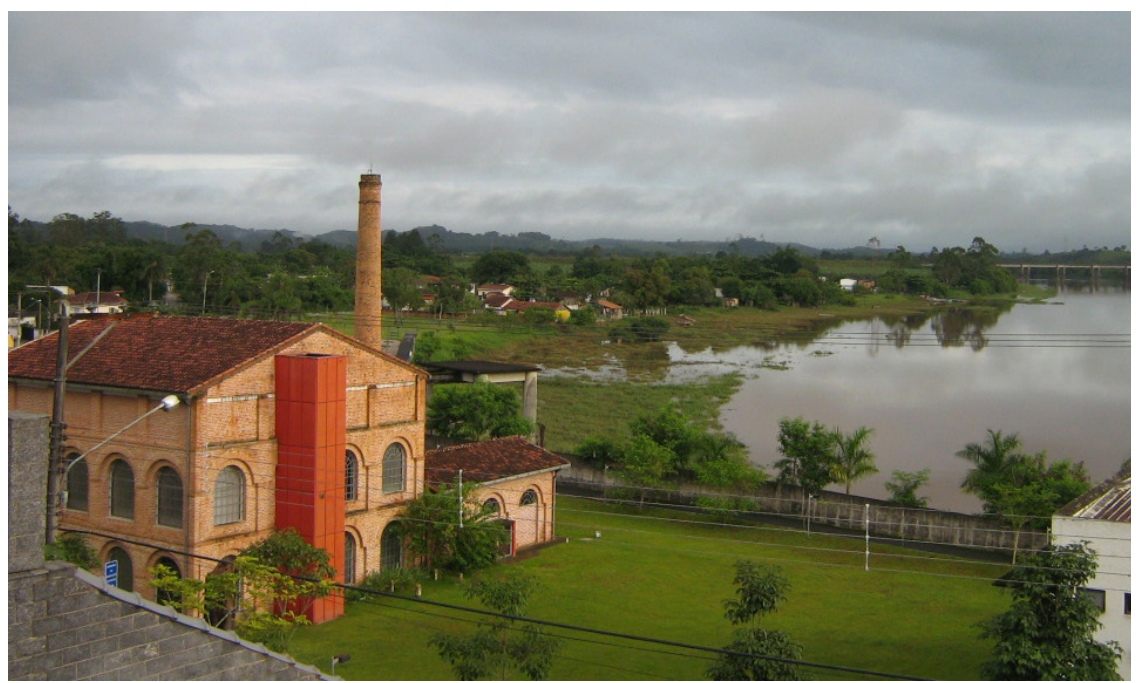

Sede da Empresa KKKK no município de Registro/ $\mathrm{SP}$ às margens do Rio Ribeira de Iguape. Fonte: o autor, 2008. 
consideradas vazias, enquanto em Sete Barras, foi um projeto privado, de capital japonês, via KKKK, que viabilizou a sua criação por meio da aquisição das terras a baixo preço.

O empreendimento colonizador nipônico deu a Registro sua condição própria de existência, até tornar-se atualidade o município economicamente mais importante do Vale do Ribeira. Em 1926 foi elevado a distrito policial, em 1934 a distrito da paz e em 1944 à condição de município, motivado pelo momento político da II Guerra Mundial.

Petrone (1966), afirma que a localidade, até o início do século XX, nada mais era que duas ou três casas de pau a pique, cujo acesso e via de transporte era exclusivamente o Rio Ribeira de Iguape. O vetor de ocupação do núcleo urbano foi o porto, junto do qual se construiu a sede da KKKK, composta por quatro galpões de armazenamento, um edifício com instalações de engenho de beneficiamento de arroz e equipamento de caldeiraria. A proximidade com o rio Ribeira garantiu, desde cedo, para as colônias meios de transporte eficiente para o escoamento da produção, já que desde meados do século $X X$ funcionava regularmente a linha de navegação a vapor entre Xiririca e Iguape, subvencionada pelo governo. AKKKK criou uma boa infraestrutura para viabilização das atividades da colônia, dentre elas a implantação de campo de experiência agrícola, no qual os japoneses introduziram culturas que vieram de sua terra natal como alho nira, berinjela nasubi, soja e arroz moti.

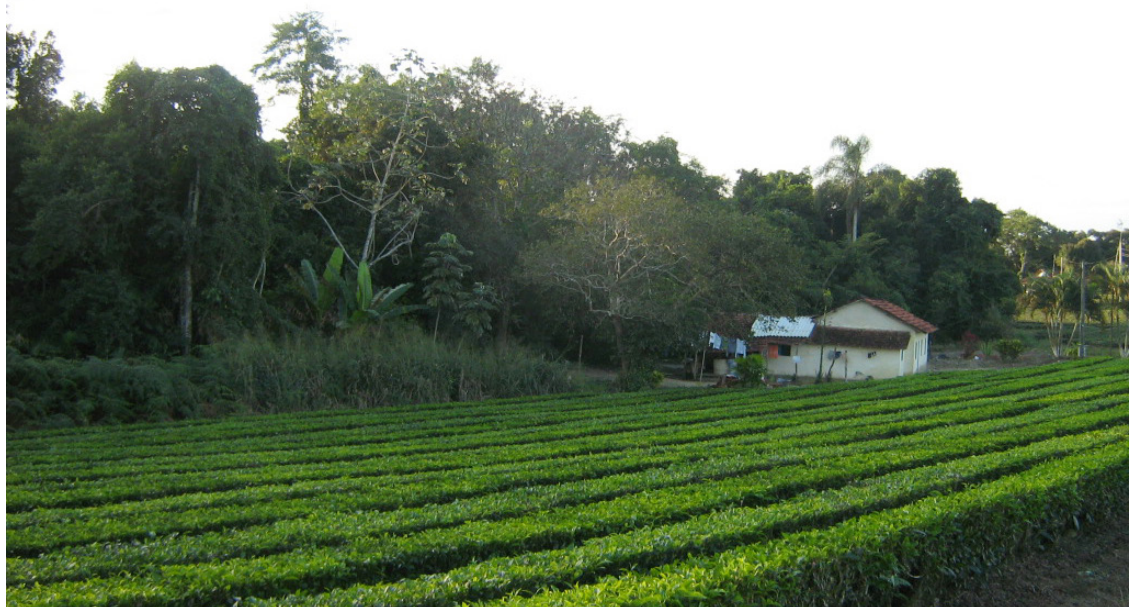


Apesar da importância do primeiro núcleo de imigração japonesa de Katsura, localizado no atual município de Iguape, foi em Registro que a colonização atingiu uma dimensão mais expressiva, constituindo-se na maior e a mais próspera das três colônias. Em terras que totalizavam 50 mil hectares, concentrou também a maior parte dos colonos japoneses, além de contar com maior estrutura por parte da empresa administradora, a KKKK. A empresa não somente loteou e introduziu as famílias nas colônias por ela administradas, como também prestou assistência técnica aos colonos nos primeiros anos de estada, criou campos de experiência agrícola (em Registro e Katsura), instalou escolas e postos médicos e, ainda nesta primeira década do século XX, adquiriu cerca de 25 mil hectares para criar a Colônia de Sete Barras.

Hoje, a Colônia de Registro ainda contém diversos vestígios materiais do auge da colonização: são antigas residências de colonos, construções que guardam uma técnica específica que alia conhecimento japonês à adaptação ao meio tropical, antigas fábricas de chá, campos de cultivo que conformam uma paisagem rural única e típica, equipamentos de infraestrutura e apoio, como é o caso dos galpões da KKKK, do porto fluvial de Registro, e edificações religiosas como a Igreja São Francisco de Assis e a Igreja Anglicana.

\section{TRABALHO NO CAMPO E PRODUÇÃO DE UMA PAISAGEM}

A paisagem à época do início da colonização japonesa pode ser traduzida como um quadro onde predominavam terras baixas, planas e suavemente onduladas, cortadas ora por pequenos córregos e ribeirões assentados em vales de fundos planos, ou por várzeas amplas como a do Rio Ribeira de Iguape. O quadro natural completava-se com um mosaico de vegetação que compreendia a exuberante mata atlântica nas colinas e terraços abrigados das cheias dos rios, ora especializando-se em bosques de caixeta junto ao baixo Ribeira, e as formações herbáceas adaptadas à constante umidade dos vargedos.

No Vale do Ribeira, os imigrantes procuraram aproveitar as condições ambientais existentes em seu próprio favor. Assim, inicialmente o terreno úmido das várzeas foi intensamente utilizado para o cultivo do arroz, um produto tipicamente ribeirinho e que demanda água em quantidade para seu desenvolvimento. Beneficiado por meio das máquinas trazidas pela KKKK, o arroz tornou-se o principal meio de vida para os colonos de Katsura e Registro. 
Em Katsura o beneficiamento era feito por meio da sociedade cooperativa, em seu engenho localizado ao lado do ancoradouro no Rio Ribeira e, em Registro, era processado nas instalações da KKKK, também situadas à beira rio, junto ao Porto Fluvial. Essas instalações representaram uma das primeiras benfeitorias trazidas pela empresa e ainda se encontram marcando a paisagem da imigração japonesa na região.

Segundo Almeida (1953), o sistema adotado na organização territorial no núcleo de Registro aproxima-se do mura do Japão rural, no qual as famílias moradoras mais próximas se integram em unidades espaciais. No caso foram cinco seções posteriormente subdivididas em quarteirões, englobando, lotes rurais e formando a Associação Japonesa de Registro. Os lugares e bairros na zona rural de Registro ainda hoje são conhecidos pelas denominações originais deste sistema espacial.

Mas a semelhança no sistema de ordenamento territorial não se reproduziu em todos os sentidos da chamada "mura" como vila rural japonesa, pois conforme discute Ono (1973), uma de suas características positivas é o fato de que a proximidade estimula uma competição entre os produtores, o que resulta na melhoria geral das condições da produção agrícola. O sentido de competição, que é forte entre os produtores, é uma atitude condicionada pela estrutura do "mura", sendo que estes não se mostram propensos à troca de informação sobre novas culturas, de acordo com o que assinala o autor.

Em Registro, o que se identifica nas experiências de produção do chá e junco é exatamente o contrário, ou seja, o espírito de cooperação entre os colonos, que foi responsável pela expansão destas novas culturas introduzidas pioneiramente ali. Para Almeida (1956:76): o espírito associativo, disposição para o trabalho e senso de responsabilidade são os traços mais positivos da cultura dominante na comunidade nipônica da baixada do Ribeira.

Além do cultivo dos produtos de subsistência já conhecidos na região, a Colônia de Registro se destacou pela introdução de um fato inteiramente novo, segundo Petrone (1966), a cultura do chá, que se tornou típica de Registro. Junto com o junco, outra espécie também plantada ali pela primeira vez no Brasil, constituem, hoje, os elementos mais marcantes da paisagem da imigração formada por campos de cultivo e antigas edificações fabris para processamento dos produtos. 
O chá ocupa os terrenos nas colinas suaves, ficando, deste modo, ao abrigo das cheias dos rios. Em geral é plantada seguindo as curvas de nível, garantindo proteção ao solo, já que com o seu crescimento, as mudas se unem formando uma cobertura densa, fechada e homogênea. A beleza da paisagem do chá em Registro é produto deste conjunto de fatores, de um lado, o sítio físico propício e, de outro, a forma como as lavouras foram dispostas. Vez em outra a uniformidade da paisagem é rompida por um trecho de mata atlântica preservado, ou nos topos ou junto ao vale de pequenos rios.

A uniformidade é dada pelos cuidados com a planta, já que desde a formação dos chazais cumprese a tarefa incansável de repor as mudas que morreram, de forma a garantir que as fileiras estejam sempre contínuas. Outro cuidado é com a altura das touceiras, mantida homogênea quando ocorrem as colheitas das folhas. O resultado é uma paisagem singular, mantida por uma forma de apropriação do espaço em consonância as características naturais dos terrenos.

A vocação natural da região favoreceu o plantio. As colinas foram a condição física que contribuiu, desde cedo, para o desenvolvimento da agricultura comercial do chá. A origem dos terrenos propiciou a formação de solos com boa drenagem, condição essencial para o desenvolvimento da cultura do chá. Essa planta arbustiva e rústica teve boa adaptação às condições naturais de Registro em terrenos com pequena declividade, chuvas regulares o ano todo e solos que não encharcam.

O plantio do chá em Registro teve início 1922, quando o imigrante japonês Torazo Okamoto, plantou as primeiras sementes da variedade chinesa (Thea sinensis), visando abastecer o consumo local por chá verde. Em 1935, ele introduziu em suas terras a variedade assam procurando atingir o mercado brasileiro, já que a variedade chinesa não produzia chá preto de boa qualidade.

As histórias da introdução destas primeiras mudas de chá assam no Brasil é no mínimo curiosa. Regressando de uma viagem de navio pelo Japão, ao passar pelo Sri Lanka, Okamoto visitou uma plantação de chá e obteve, a muito custo, algumas sementes desta variedade. Como não era permitido embarcar com as sementes, escondeu-as dentro de um pão e, na viagem de volta, conseguiu fazê-las brotar. Ao desembarcar no porto de Santos, Okatomoto tinha em mãos 65 mudas de chá, as quais foram as matrizes de uma variedade que se espalhou por Registro. Essas matrizes encontram-se ainda hoje protegidas

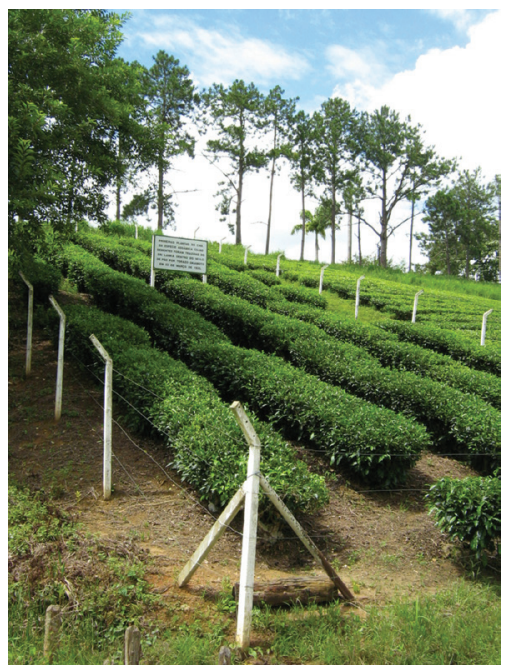

63 pés de chá da variedade. Assam trazidos por Torazo Okamato para Registro em 1935. Tombadas pelo Iphan em 2010. Fonte: as autoras, 2008 


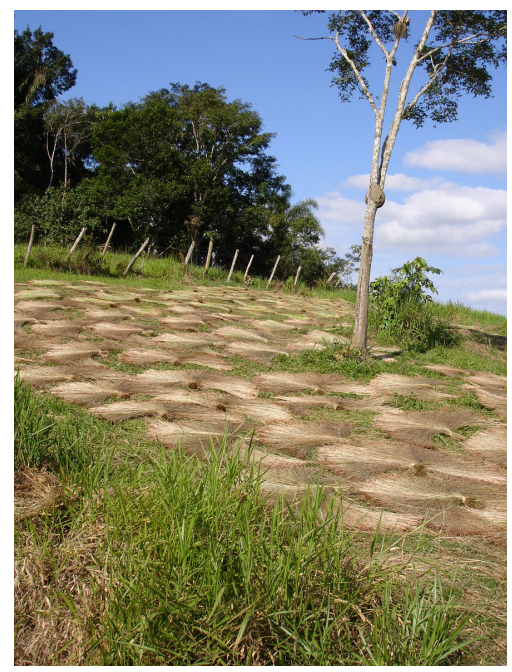

Junco secando, Registro/SP. Fonte: as autoras, 2008. e preservadas em um canteiro cercado, no interior da Fazenda Chá Ribeira, da família Okamoto. O sucesso de Okamoto com o chá preto estimulou vários colonos a plantarem em suas próprias terras.

Durante a segunda guerra, as dificuldades com o comércio internacional no Pacífico, estimularam a exportação do chá de Registro, transformando o Brasil, da condição de importador em exportador. Nesta época Registro chegou a ter 42 fábricas de chá, a maior parte de pequeno porte e espalhadas pelos bairros rurais. A expansão do cultivo em Registro foi de tal ordem que o município concentra a quase totalidade da produção do Brasil: entre $98 \%$ e $99 \%$ do chá preto exportado pelo Brasil vem do Vale do Ribeira, e na região, Registro destaca-se como o grande produtor. A produção em Registro se concentra, hoje, entre pequenos e médios proprietários, em propriedades de 20 a 50 hectares, muitos dos quais vendem sua produção para as fábricas que funcionam no município.

Semelhante história de plantio pioneiro no Brasil tem o junco. Ele foi introduzido pelo imigrante Shigeru Yoshimura, em 1931, com mudas trazidas de Okiyama para Registro, embrulhadas em pedaço de estopa escondida no bolso. Plantadas as mudas, Yoshimura distribuiu-as entre companheiros de viagem formando plantações que se espalharam pela colônia. As condições ecológicas locais representaram uma vantagem na produção do junco, já que com abundância de calor e umidade, a possibilidade de colheita ampliou-se em três vezes por ano, ao contrário do Japão em que ocorre apenas uma vez.

Para beneficiar o produto, em 1934, a Kaiko providenciou um tear apropriado dando início a produção de um artigo até hoje tipicamente regional: as esteiras. Toda a produção sempre foi e ainda é familiar, pais e filhos trabalham junto no plantio, colheita e beneficiamento. $O$ processo de confecção das esteiras inicia com uma máquina, onde a haste é repartida em duas, ficando mais finas. Depois são espalhadas sobre um terreiro, para secar, quando adquirem um tom marrom.

O Vale do Ribeira se tornou o único produtor desse tipo de junco na Américas, todo ele resultado das matrizes trazidas por Yoshimura. Além das famosas esteiras e dos chinelos de junco, a produção diversificou, a partir de um projeto em conjunto com o Sebrae. Hoje estão sendo produzidos bonés, chapéus, puffs, almofadas, mochilas. Mas nem todos aderiram ao projeto e a família Yoshimura, por exemplo, preferiu continuar mantendo a tradição dos chinelos e esteiras. 
Em reportagem recente para um jornal paulista, o Sr. Yoshimura explica que o pai poderia ter plantado sozinho, em Registro, o junco trazido do exterior, detendo assim o monopólio do produto. Mas que, ao contrário, preferiu dividir sua experiência com os conterrâneos. "É costume japonês repartir com os outros", disse ele, explicando a atitude do pai, que favoreceu a expansão do junco pelo município (Revista da Folha, 15/06/2008).

O junco é encontrado hoje, plantado nos vales de fundo plano que separa as colinas suaves de Registro. Sua textura e altura uniforme formam uma espécie de tapete verde nestes fundos de vale. Em seu processo de beneficiamento, que começa com a secagem ao sol, em terreiros ou em encostas suaves das colinas, mantém sua textura uniforme, agora em tons amarronzados. Em ambos os momentos da produção, o junco conforma uma paisagem típica e única, de grande beleza e ao mesmo tempo enorme simplicidade.

A partir da adoção do chá como forma de cultivo pelos colonos japoneses, incrementada após o fracasso da produção de café na região e a alta do preço internacional do chá após a crise de 1929, estabeleceu-se uma nova tipologia industrial: a fábrica de chá. Aquelas construídas em Registro remetem diretamente ao empreendimento colonizador de Registro e fazem parte dos processos históricos de adaptação e recriação do meio. O conjunto das terras cultivadas, junto com as fábricas e residências, é exemplar das relações entre

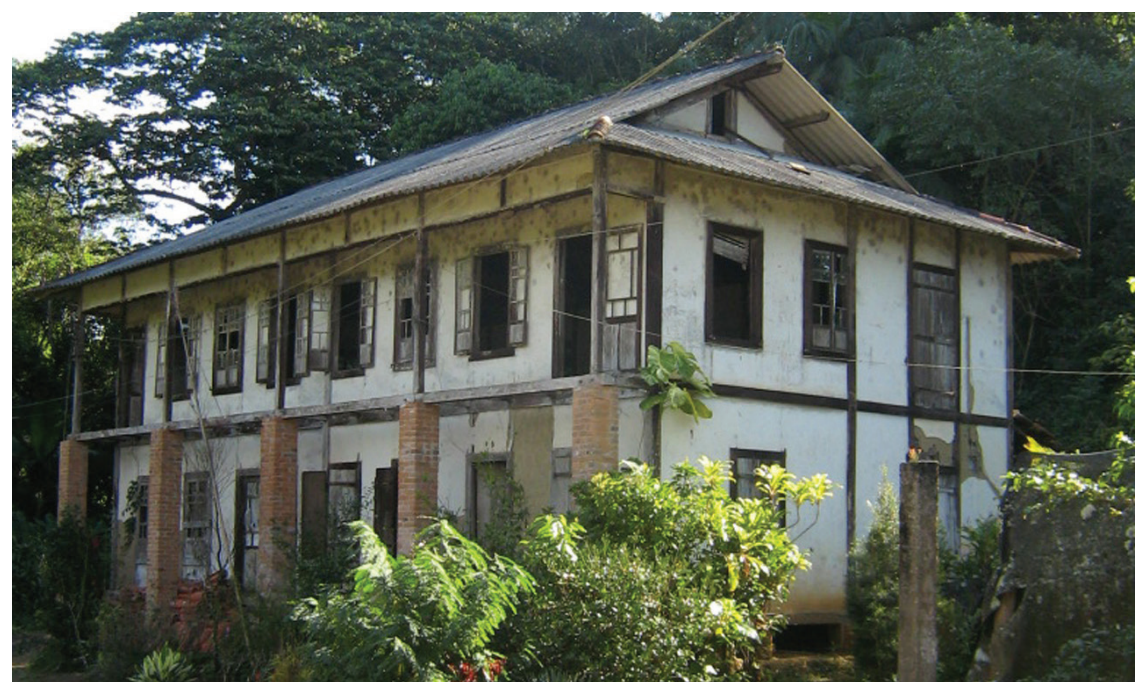

Fábrica de Chá Shimizu, Registro/SP. Fonte: as autoras, 2008. 
comunidade-natureza, na quais a paisagem aparece como trabalho do produto humano a partir da natureza como matéria prima. Importante destacar que a paisagem traz a marca das diferentes temporalidades da relação sociedade-natureza, aparecendo, assim, como produto de uma construção que é social e histórica e que se dá a partir de um suporte material, a natureza. A natureza é matéria-prima a partir da qual as sociedades produzem a sua realidade imediata, através de acréscimos e transformações a essa base material. Nesse sentido, a perspectiva da paisagem cultural implica em que se identifique as relações estabelecidas, nos vários momentos históricos, entre as comunidades locais e a natureza, considerada matéria-prima para a apropriação social.

As fábricas de chá são grupo de edificações fabris extremamente importantes na ocupação da região, presentes como atividade principal ou como alternativa econômica ao café desde praticamente os momentos iniciais da imigração. Diversas foram alteradas ou demolidas, e, em geral, não conservam as características originais.

As fábricas de chá que compõem a paisagem cultural do município de Registro são, grosso modo, galpões para o abrigo do maquinário e com área para o murchamento das folhas. Estas são as instalações mais características das fábricas de chá, pois se compõe de um salão amplo em que se dispõem os brotos para murchamento e desidratação por meio de ventilação natural. Não se sabe muito sobre os processos de elaboração destas construções. Kuniyoshi, Segawa e Pires (1985) apontam que à época da instalação das mesmas, técnicos japoneses vieram ao país para orientar os produtores. Acredita-se que dessa orientação veio o partido assobradado das edificações, com salão superior livre de pilares centrais e térreo para processamento das folhas. As fábricas apresentam dimensões semelhantes, cerca de 7 x 14 metros e as técnicas construtivas, em geral, são as mesmas empregadas das moradias, estrutura independente de madeira, com vedações em taipa ou tijolos.

A fábrica de chá Shimizu foi construída para ter dupla função, abrigar a família e a fábrica de chá e é dos exemplares arquitetônicos fabris que apresenta o maior apuro técnico e cuidado plástico. A edificação foi construída pelo Sr. Sojiro Shimizu, que chegou ao Brasil em julho de 1925 por meio do empreendimento da KKKK, aos 38 anos. Inicialmente aventurou-se no cultivo do café, para depois iniciar a plantação e processamento do chá. Como os demais imigrantes, habitou de pronto uma casa provisória, próxima de onde está a fábrica. Com o incremento do chá, contratou o mestre-carpinteiro Minoru Ushino para executar a obra do 
edifício em questão que passou a abrigar a família. Segundo relato do Sr. Toshiro Shimizu, filho de Sojiro Shimizu e atual proprietário da casa, seu pai entregou o projeto ao carpinteiro para que ele fizesse a casa conforme seu desejo, já que o mesmo estava prestes a parar de trabalhar como carpinteiro.

O edifício organiza-se em dois pavimentos, conforme a tipologia das fábricas de chá, tendo as dimensões de $7 \times 14$ metros, obedecendo ao padrão das demais. É realizado em estrutura independente de madeira, com vedações em taipa de mão e suspende-se $30 \mathrm{~cm}$ do piso por embasamento de tijolos maciços. Uma varanda em madeira ocupa todo o segundo pavimento da fachada principal. Está colocada à frente do volume prismático e suspendese do piso por pilares em tijolos aparentes, o que lhe confere certa monumentalidade. As envasaduras são em madeira canela, de tom escuro, tendo as janelas sistema de abrir e fechar, conjugando vidro e madeira, o que é raro nos casos estudados. Ostenta telhado irimoya, cujas telhas de barro foram substituídas por fibrocimento.

O complexo fabril Amaya é dos maiores ainda em atividade na região. Diversos galpões de proporções retangulares e quase todos com um pavimento são dispostos em forma de "U". No meio deste, situa-se a residência original da família, construída segundo a técnica e estética oriental. Nos galpões pode-se perceber alguns vestígios da tecnologia japonesa de sambladuras, sobretudo nas coberturas, como no galpão situado mais ao fundo do terreno. No geral, estão modificados pelas reformas impostas pelas adaptações tecnológicas de processamento de chá. Uma pequena construção na lateral dos galpões, junto à chaminé de tijolos aparentes, tem o telhado irimoya, característico das construções japonesas.

A proximidade do espaço de residência ao local de trabalho era dada pelas próprias condições da colonização dos imigrantes, que vinham para trabalhar no campo como proprietários de suas terras. Trabalho e moradia estavam próximos, mas raramente na mesma edificação. A casa de residência do colono era a edificação mais simbólica do complexo rural, pois era a apropriação do território pelos imigrantes, a face visível se seus desafios culturais no novo país. No processo de ocupação do território e adaptação ao meio, as casas são elementos fundamentais de ressignificação dos universos. Para Almeida (1953), a ausência ou presença de certos materiais de construção, as possibilidades econômicas e as condições climáticas levaram a certos tipos de moradia, que são exemplares dos processos mais globais de transformação e também de mostrar os próprios saberes, valores, expressões e técnicas. 
A arquitetura dos imigrantes japoneses, construída no início do século $X X$, é exemplo da diversidade e singularidade arquitetônica do Vale do Ribeira. São edificações que revelam a trajetória da ocupação de um território considerado vazio, "à margem do império do café" (PAPY, 1953) e são feitas a partir das peculiaridades dos próprios imigrantes orientais. Alguns destes eram exímios carpinteiros, com grande destreza nas técnicas da madeira. Mesmo utilizando algumas das técnicas já conhecidas em terras brasileiras, o fizeram conferindo as marcas de sua própria cultura e conhecimento. Sua arquitetura não é testemunho apenas dos processos políticos e sociais de imigração. Ela é também exemplar das formas de construir e da tecnologia dos imigrantes. No processo de ocupação do território e adaptação ao meio, as casas são elementos fundamentais de ressignificação dos universos. Para Almeida (1953), a ausência ou presença de certos materiais de construção, as possibilidades econômicas e as condições climáticas levaram a certos tipos de moradia, que são exemplares dos processos mais globais de transformação e também de exposição dos próprios saberes, valores, expressões e técnicas.

\section{A CASA DO COLONO}

A Colônia de Registro, chamada Registro-Gô, era dividida em cinco seções, denominadas Ku, que tinham em torno de 1.200 alqueires. As seções tinham o nome de: $1^{\mathrm{a}}$ Itibu (Centro), $2^{\mathrm{a}}$ Niibu

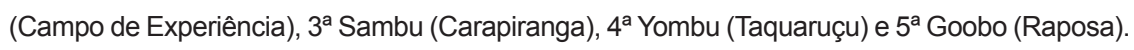
Estas eram subdivididas em Kumi, como que "unidades de vizinhança", compostas por pequeno número de famílias e organizadoras da vida comunitária. No eixo de cada Seção estava a Praça Rural com o Centro de Convivência, o Kaikan, espaço das atividades comunitárias e, num raio de cerca de 2,5 quilômetros, localizava-se a escola. (Aoki, 2006; KKKK, 1932)

Não há vestígios materiais mais evidentes desta subdivisão do município de Registro, tão pouco dos equipamentos comunitários, que foram demolidos ou descaracterizados. Os nomes de alguns bairros como Campo de Experiência são o testemunho desta organização territorial inicial realizada pela KKKK. As propriedades tinham por volta de 10 alqueires (24,2 hectares), dispostas em lotes estreitos e compridos, com proporções retangulares, com $200 \mathrm{~m}$ de testada por $1.000 \mathrm{~m}$ de profundidade, em geral, próximos a águas correntes superficiais. Segundo Kuniyoshi, Segawa e Pires (1985), a ocupação inicial obedeceu ao 
ritmo da chegada dos imigrantes, sendo primeiro ocupados os terrenos mais próximos ao núcleo urbano e ao porto e posteriormente os mais distantes.

A primeira morada do colono estava dentre as preocupações da KKKK, que estabelecia suas dimensões e características básicas. As medidas das casas eram baseadas em modelos bidimensionais definidos pela medida do tatame, de formato retangular, de 1 ken $(1,80 \mathrm{~m})$ x ó ken $(0,90 \mathrm{~m})$. A casa recomendada pela KKKK, para uma família de 5 pessoas, deveria ter 5 ken $(9 \mathrm{~m}) \times 3$ ken $(5,40 \mathrm{~m})$. A casa, em duas águas, deveria ser construída em palmeira jiçara amarrada com cipó. $\mathrm{O}$ interior dividia-se em três partes: área de trabalho, que ocupava a maior porção, a cozinha e um aposento de piso elevado. Esta divisão interna, desde o princípio, conforme as indicações da KKKK, reiteradas pela própria tradição, remetia às construções rurais japoneses. (YAMAKI, 2000 Apud AOKI, 2006)

De acordo com Rogério Gonçalves, apesar do auxílio técnico da KKKK, as primeiras casas e até mesmo o início do plantio, baseavam-se em métodos empíricos. Esta primeira casa remetia às construções dos caboclos da região, cujas técnicas de construir eram amplamente utilizadas.

Para implantação da casa, primeiramente era desmatado o terreno. Há que se ter em conta as inúmeras dificuldades para o estabelecimento, tendo em vista as diferenças entre geográficas e culturais. Conhecer a terra, seus materiais, além da própria língua era árdua tarefa. É o que mostra o relato de Yonosuke Yamada, gerente da KKKK falando sobre Registro:

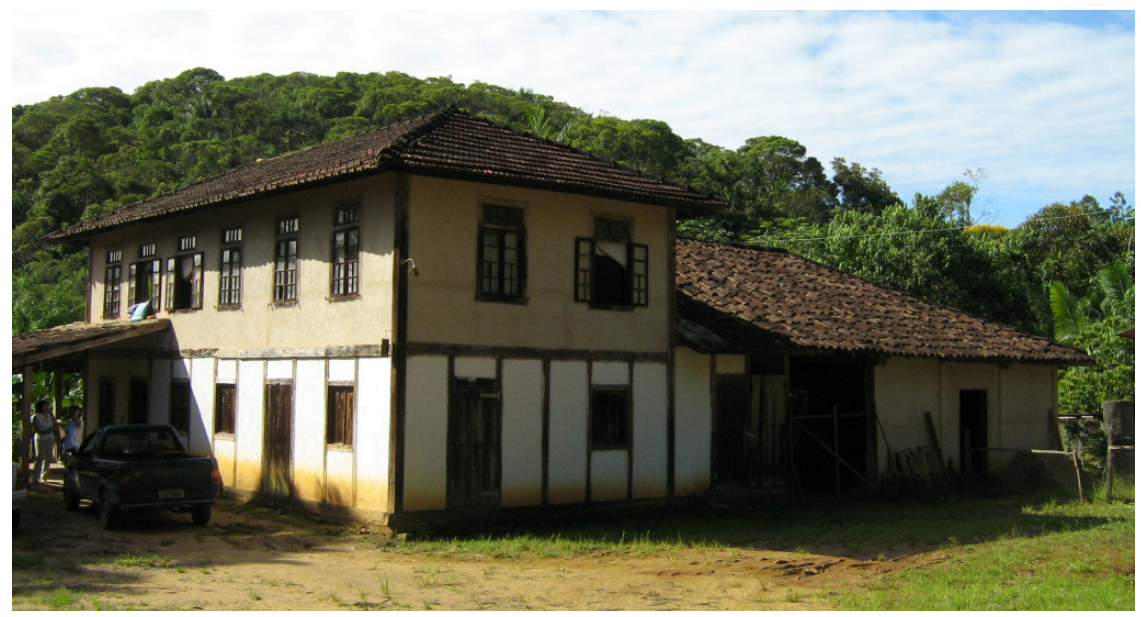


No insipiente núcleo de colonização tive oportunidade de sentir pessoalmente a energia dos colonizadores. A meus olhos recém-chegados do Japão, esta mobilização geral apresentava-se como algo inédito, ao mesmo tempo que me vi obrigado a reconhecer que a tarefa da colonização exige dos emigrantes, no exterior, uma extrema firmeza de propósitos e uma imensa dose de obstinação. (Handa, 1987: 344)

A precariedade da primeira casa advinha não da falta de conhecimento técnico construtivo, mas da falta de intimidade com o meio físico. As dificuldades tinham início na derrubada do terreno. Logo os colonos perceberam a impossibilidade de com apenas os membros da família, e com os instrumentos que tinham, de proceder ao desmatamento. Sem o manejo experiente do machado e conhecimento da mata, passaram a recrutar a mão-de-obra do caboclo.

Assim que o imigrante atingia certo poder aquisitivo, o que poderia demorar em torno de cinco, tinha início o processo de construção da segunda moradia. Esta era construída com mais vagar, empregando-se explicitamente as técnicas construtivas japonesas. Embora tenham vindo alguns mestres carpinteiros entre os imigrantes trazidos pela KKKK, não se tem muita informação sobre a sua atuação na região. O domínio da carpintaria era habilidade de muitos japoneses (técnica secular de sua cultura), que, ao chegaram no Brasil, empregaram estes conhecimentos na construção de suas casas. Segundo Rogério

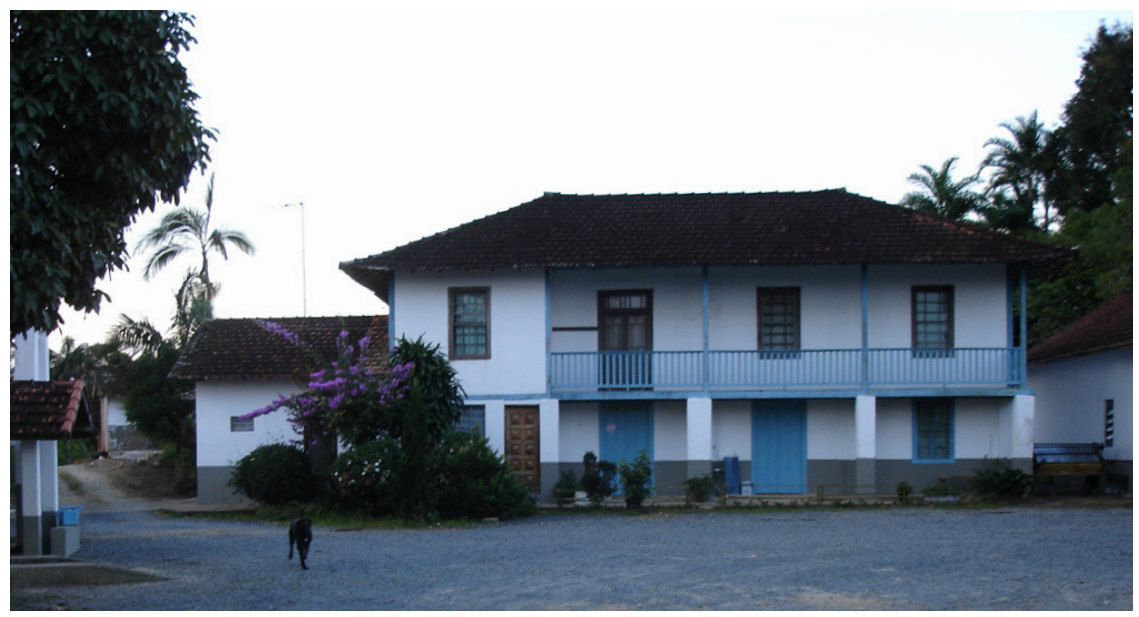


Gonçalves (2003), uma das razões para a arquitetura japonesa chamar a atenção do mundo ocidental é o domínio do arquiteto-carpinteiro (conhecidos no Japão como Daiku) dos materiais construtivos, sobretudo da madeira. O mestre imigrante mais famoso no Brasil do qual há dados biográficos e profissionais, é Kazuo Hanaoka, carpinteiro especializado em restauro e manutenção de palácios japoneses. No Brasil, construiu o Casarão do Chá, cuja cobertura mescla três modelos tradicionais de coberturas palacianas. No caso de Registro, embora haja notícias de mestres-carpinteiros bastante habilidosos, o que é facilmente verificável pela arquitetura pesquisada, informações mais substantivas perderam-se no tempo. Os colonizadores, em sua maioria, fizeram as vezes de carpinteiro para erguer suas primeiras habitações. Após algumas experiências aplicadas na construção da primeira morada, em que a técnica e os conhecimentos do caboclo preponderaram, na casa definitiva estão explícitas as técnicas orientais. (KUNIYOSHI, SEGAWA \& PIRES, 1985)

No espaço cotidiano no morar do colono estão evidenciadas de modo marcante as relações entre a tradição local e as técnicas dos imigrantes, materializados em edificações de singularidade plástica e construtiva. Encontramos diversos exemplos (cerca de 20 propriedades rurais) muito significativos desta arquitetura, cujo estado de preservação e conservação é bastante variado.

Em face do que foi construído em Registro e lguape, este número é muito pequeno. Os fatores que contribuíram para sua deterioração foram a agressividade do clima, as características dos materiais empregados e seus procedimentos construtivos, como modulação e sambladuras estruturais, os quais pressupunham a constante manutenção e substituição (Gonçalves, 2003). As residências da família Rokugawa, Amaya, Fukasawa, do Sr. Gozo Okiyama e da Sra. Susu Okiyama são representativas por terem entre si grande diversidade de soluções, ao mesmo tempo em que conservam a unidade enquanto arquitetura da imigração japonesa. Todas são ricas no que se refere à técnica e à plasticidade. São construídas com estrutura autoportante em madeira, com madeiramento encaixado (sambladuras) sem a utilização de pregos, e com vedações em pau-a-pique, com palha do arroz misturada ao barro. $\mathrm{O}$ telhado era feito primeiramente em palha, sendo substituído por telhas de barro, e, mais recentemente por fibrocimento. A estrutura das casas é suspensa do chão por embasamento que pode ser em tijolos ou em pedra. Pelas transformações culturais e os constrangimentos históricos (como as políticas estabelecidas para os imigrantes japoneses a partir da II Guerra 
Mundial) acesso a materiais industrializados e progressivo abandono das casas para moradia em edificações novas, construídas em alvenaria de tijolos, as tradições de manutenção das casas antigas foi perdendo, pouco a pouco, o hábito de ser realizada.

\section{COTIDIANO NO DOMÍNIO DA TROPICALIDADE: A VIDA RELIGIOSA}

Completam o quadro da paisagem cultural do imigrante japonês no Vale do Ribeira outra série de edificações ligadas à sua vida cotidiana que são os espaços de religiosidade. A empresa KKKK no processo de ocupação do território não apenas loteou a área rural para as propriedades dos imigrantes, como também foi responsável pela urbanização da cidade de Registro, que era uma localidade de ocupação insipiente. Desde as primeiras ocupações do território brasileiro no período de colonização, o elemento religioso, a igreja, domina a paisagem e a composição dos núcleos urbanos. Curioso observar que a KKKK também foi a responsável pela construção da Igreja de São Francisco de Assis, no alto do Morro da Espia, organizando a arrecadação de recursos junto à comunidade e, inclusive, junto a católicos mais influentes e empresas do Japão.

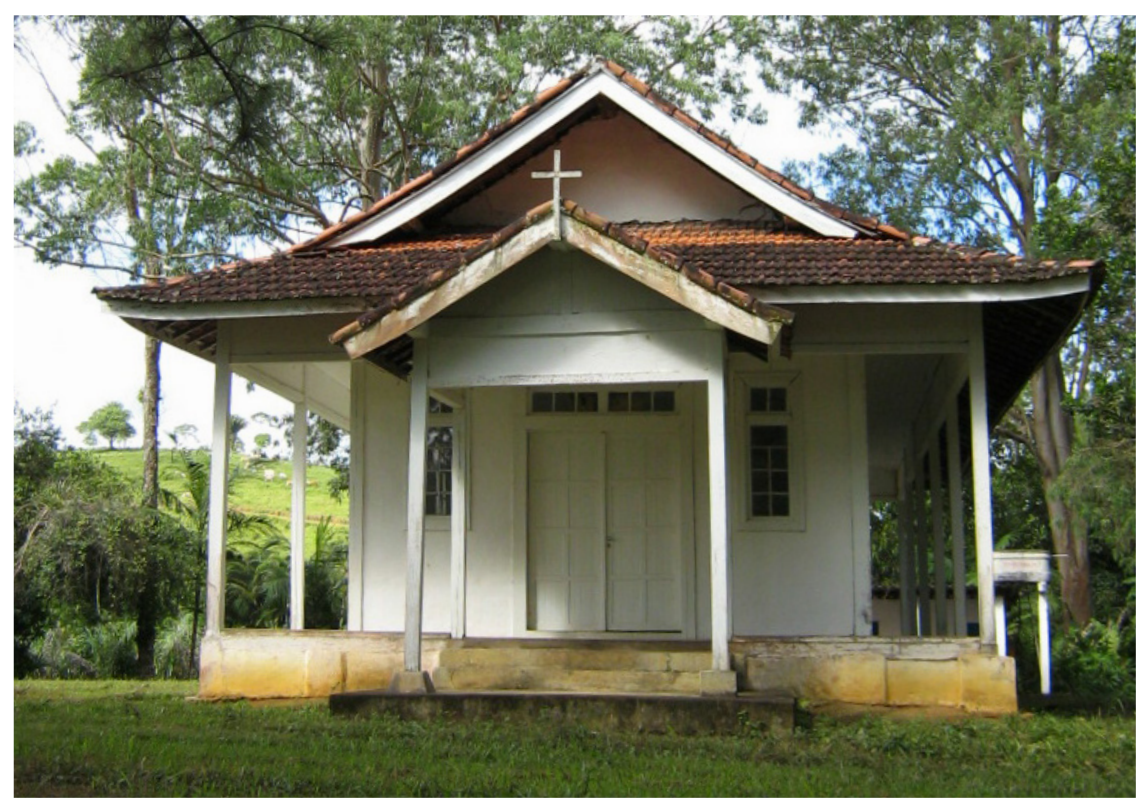


A pedra fundamental foi lançada em 1926 em razão da quantidade de adeptos do catolicismo e a necessidade de mostrar a integração dos imigrantes à nova terra.

Para Mori (1992), a construção de igrejas católicas em áreas de colonização japonesa no território paulista, como ocorreu em Registro, Promissão e Álvares Machado, significava mais uma manifestação da vontade de adaptação ao ambiente brasileiro do que propriamente uma conversão ao catolicismo. Do ponto de vista psicológico, segundo esse autor, certamente se assemelha a ter construído um templo. Segundo Midorikama, os colonos de Registro dividiam-se, do ponto de vista religioso, em católicos, protestantes e budistas, sendo os primeiros mais numerosos, total superior a um terço dos habitantes.

A Igreja de São Francisco Xavier, implantada no topo do Morro da Espia, próxima aos galpões e ao engenho da empresa, representa o esforço de integração e de construção de símbolos religiosos que coadunassem com os valores brasileiros. Com a construção da igreja católica, a empresa KKKK, buscava criar no espaço da Colônia de Registro, estruturada com princípios e lógicas espaciais japonesas, certo modo de simbolismo urbano local. Como as cidades setecentistas brasileiras, implantadas pelos portugueses, Registro também teria símbolo religioso de destaque, visível a quem acessasse a cidade pelo rio Ribeira de Iguape e de diversos pontos do núcleo urbano.

Diferentemente da Igreja Episcopal, da qual falaremos a seguir, e das inúmeras residências da colônia, não há referências às técnicas e à estética da arquitetura japonesa. No centro da fachada simétrica, duas pilastras retas emolduram a porta e a imagem de São Francisco Xavier. A escolha do santo padroeiro da igreja é também revestida de simbolismos. São Francisco Xavier, co-fundador da Companhia de Jesus, foi um dos mais importantes missioneiros católicos, cujo epíteto é "Apóstolo do Oriente", por ter pregado no oriente e morrido na China.

O templo religioso tem grande significado para a comunidade japonesa do município que é composta de muitos católicos. Estes reconhecem a igreja como construção efetiva dos japoneses, já que feita com recursos da própria comunidade.

A Igreja de São Francisco Xavier foi erguida praticamente em conjunto à Igreja Episcopal, a qual corresponde a expectativas e objetivos diversos. Ela é muito distinta da Igreja de São Francisco Xavier, revelando o caráter da religiosidade dos imigrantes e seus processos históricos de adaptação e transformação. Se a Igreja de São Francisco Xavier, erguida no 
centro de Registro, junto à sede da empresa KKKK remete ao esforço de conjugação com os valores religiosos brasileiros do catolicismo, a Igreja Episcopal mostra os esforços dos colonos de manutenção da própria cultura e religiosidade.

$\mathrm{Na}$ arquitetura de cada templo religioso estão expressas as religiosidades distintas dos imigrantes e seus modos de estabelecimento em terras brasileiras. A Igreja Episcopal de Todos os Santos localiza-se a 15 quilômetros da cidade de Registro. A história da Igreja iniciase com a chegada, em 1923, do missionário João Yassoji Ito a Registro. Ito, sendo natural de Nagano, no Japão, veio para a região para ser missionário, também em razão da presença de seus irmãos que vieram ser colonos no empreendimento da KKKK.

Com o trabalho missioneiro crescendo e ganhando fiéis na colônia, o missionário contou com a ajuda de duas famílias, Ikegami e Fukasawa, ambas com participação direta no processo de construção do templo. Com a doação do terreno para construção da igreja por parte do Sr. Ikegami, em setembro 1927 foi lançada a pedra fundamental da Igreja, com a presença do Bispo Thomas. O lote onde está a igreja fazia parte da propriedade da família, que antes de habitarem a casa que ainda existe junto ao edifício religioso, já havia construído uma primeira morada. Ela foi edificada pelo mestre-carpinteiro Wada, o mesmo que realizou, alguns anos depois a casa da Família Fukasawa, e mão de obra utilizada foi a própria comunidade de imigrantes. Em 1929 foi inaugurada esta que é para alguns, a primeira igreja construída por imigrantes japoneses no Brasil. Apresenta grande riqueza de detalhes construtivos empregados pelo mestre-carpinteiro que a construiu. A estrutura independente em madeira encaixada e vedações em taipa de mão, ergue-se cerca de $30 \mathrm{~cm}$ do solo por pilares de tijolos maciços. $O$ acesso se dá pelo guenkan, elemento da arquitetura japonesa vestíbulo de entrada, onde eram retirados e deixados os sapatos.

A varanda, cuja cobertura é extensão da cobertura da própria casa, circunda a face frontal e as duas laterais. O telhado tem desenho irimoya, cuja empena que tradicionalmente serve à ventilação, é fechada. No topo desta, conforme podemos verificar nas fotografias de época localizava-se a cruz, assim como na ponta da cumeira do guenkan. Hoje há apenas esta última cruz. O espaço religioso foi utilizado também como escola primária de ensino bilíngue para as crianças do bairro. Todo o mobiliário bancos e mesas foi desenhado e executado à época de construção da igreja. Realizados com sambladuras com encaixer tipo "asa de andorinha" ou alma encavilhada são raros exemplares de bens móveis da colônia japonesa que sobreviveram ao tempo. 


\section{CONSIDERAÇÕES FINAIS}

O estudo sobre os bens culturais da imigração japonesa na região do Vale do Ribeira é exemplo eloquente dos esforços metodológicos para entendimento dos bens culturais no âmbito dos conceitos da paisagem cultural. Tal como estruturado ao longo do trabalho, a paisagem cultural do Vale do Ribeira representa a íntima relação estabelecida entre os vários grupos sociais ali presentes com a natureza, relação que explica como se deu a produção dos objetos materiais e da vida imaterial.

A ocupação pelo imigrante japonês no Vale do Ribeira é um dos momentos de constituição da paisagem do Vale do Ribeira, cujos tempos foram acumulados desigualmente, para usarmos o conceito de Milton Santos (1986). Buscamos mostrar ao longo do artigo que as marcas desta imigração ainda estão presentes na paisagem dos campos de cultivo do chá e junco, dois produtos trazidos pelos imigrantes e que foram fundamentais à reprodução social do grupo. O chá conforma uma paisagem única e típica em Registro (Petrone, 1966). Os chazais foram plantados nos terrenos das colinas suaves, ficando, deste modo, ao abrigo das cheias dos rios. A beleza da paisagem do chá em Registro é produto deste conjunto de fatores: de um lado, o sítio físico propício e, de outro, a forma como as lavouras foram dispostas.

Já o junco ocupa os vales de fundo plano que separam as colinas. Sua textura e altura também uniformes formam uma espécie de tapete verde nos fundos de vale encharcados. Ambos os produtos foram trazidos por imigrantes japoneses que poderiam ter se tornado os únicos produtores em toda a região, monopolizando a oferta. No entanto optaram por distribuir mudas entre seus conterrâneos, tornando a região a maior produtora nacional destes tipos de produtos. Ao se disseminar as plantas entre outros agricultores japoneses da região, as mudas tornaram-se símbolo do espírito de cooperação e do sentido coletivo que envolvia cotidianamente a vida daqueles imigrantes japoneses, assentados sob o domínio da tropicalidade no sudeste brasileiro e marcaram definitivamente a paisagem cultural do Vale do Ribeira.

Ao optarmos pelo Vale do Ribeira como uma área de pesquisa e atuação profissional no âmbito do Instituto do Patrimônio Histórico e Artístico Nacional o enfoque da paisagem cultural mostrou-se o mais pertinente para tratar as questões do patrimônio na região, já 
que possibilitou um olhar a partir do território pressupondo o reconhecimento das relações singulares entre os grupos sociais e a natureza. Um dos resultados deste estudo o tombamento de "14 Bens Culturais da Imigração Japonesa nos municípios de Registro e Iguape/SP" como representativos da imigração japonesa no Vale do Ribeira, que foi aprovada pelo Conselho Consultivo do Iphan em julho de 2010. Além da fundamental legitimidade, importância e ineditismo do reconhecimento de tais bens culturais como política pública de patrimônio cultural, o tombamento era também um recurso de presença do Iphan na região. Os tombamentos realizados em áreas de valor como paisagem cultural, assim como no caso dos bens da imigração no Vale do Itajaí em Santa Catarina serviriam ao Iphan como "âncoras do território". Eles são, portanto, uma parte do projeto mais amplo da Paisagem Cultural do Vale do Ribeira que visava compreender como bens culturais as já ditas relações singulares entre os grupos sociais e a natureza. Sem o reconhecimento da paisagem cultural do Vale do Ribeira corre-se o risco de pouco termos avançado nas políticas de patrimônio nacional. Há o perigo eminente de os espaços dos imigrantes japoneses serem reificados como objetos isolados, distantes do que se espera de uma memória plural, representativa de diversos grupos que compõem a sociedade brasileira, excepcional e monumentalizada. 


\section{REFERÊNCIAS BIBLIOGRÁFICAS}

ALMEIDA, V. U. (1953). "Condições de vida do pequeno agricultor no município de Registro". São Paulo: Comissão Nacional do Bem-Estar Social / Ministério do Trabalho, Indústria e Comércio.

AOKI, A. (2006). "Paisagens de Registro. Identidade e Preservação". Londrina: Trabalho Final de Graduação em Arquitetura e Urbanismo, Universidade Estadual de Londrina.

GONÇALVES, R. (2008). "O sincretismo de culturas sob a ótica da arquitetura vernácula do imigrante japonês na cidade de Registro". São Paulo: Anais do Museu Paulista. N. Ser. Vol. 6, n.1, p. 11-46. Jan-jun. HANDA, T. (1987). “O imigrante japonês. História de sua vida no Brasil”. São Paulo: T.A. Queiroz/ Centro de Estudos Nipo-Brasileiros.

HASEGAWA, T.; RUEDA, J. (1932). "Introdução dos imigrantes japoneses no Brasil e seu órgão instrutivo". São Paulo: KKKK. Atividades da Kaigai Kogyo Kabushiki Kaisha em São Paulo.

IPHAN (2008). Dossiê de Tombamento Bens Culturais da Imigração Japonesa em Registro e Iguape, São Paulo. São Paulo: Superintendência do Iphan em São Paulo.

IPHAN (2009). Dossiê Paisagem Cultural do Vale do Ribeira. São Paulo: Superintendência do Iphan em São Paulo.

KUNIYOSHI, C.; PIRES, W. (1984) “Casarão do Chá. Mogi das Cruzes”. São Paulo: Condephaat.

KUNIYOSHI, C.; SEGAWA, H.; PIRES, W. (1985). "Arquitetura da imigração japonesa”. São Paulo: Projeto, (72):99-104, fev.

MIDORIKAWA, J. T. (1928). "As colônias japonesas na zona do Ribeira de Iguape”. Seção de Obras do Estado de São Paulo.

MORI, K. (1992). "Vida religiosa dos japoneses e seus descendentes residents no Brasil e religiões de origem japonesa. In: Uma epopéia moderna. 80 anos da imigração japonesa”. São Paulo: Hucitec/ Sociedade Brasileira de Cultura Japonesa.

DO NASCIMENTO, F. B.; SCIFONI, S. (2010). "A paisagem cultural como novo paradigma para a proteção: a experiência do Vale do Ribeira-SP”. São Paulo: Revista CPC, n. 10, p. 29-48, maio/out.

PAPY, L. (1957). "À margem do império do café”. Boletim geográfico, ano XV, nº 137. 
ID_PESQUISAS

PETRONE, P (1961). "Notas sobre os sistemas de cultura na Baixada do Ribeira". São Paulo: Boletim Paulista de Geografia ${ }^{\circ} 39$, pp.47-63.

PETRONE, P. (1966). "A baixada do Ribeira. Estudo de Geografia Humana”. São Paulo: Boletim nº 283. Geografia $n^{\circ}$ 14. FFLCH/USP.

SANTOS, M. (1986). "Por uma Geografia Nova: da crítica da Geografia a uma Geografia". São Paulo: HUCITEC. Crítica. $3^{\text {a }}$ edição.

YAMAKI, H. (1997). Verbete Japanese. In: OLIVER, Paul. Enclyclopedia of Vernacular Architecture of the World. Cambridge University, 1997, vol. 3. 